\title{
Nutrition, Metabolism, and Fertility in Dairy Cows: 3. Amino Acids and Ovarian Function
}

\author{
P. C. Garnsworthy, ${ }^{* 1}$ J. G. Gong, † D. G. Armstrong, † J. R. Newbold,‡ M. Marsden,§ S. E. Richards,\# \\ G. E. Mann, ${ }^{\star}$ K. D. Sinclair, ${ }^{*}$ and R. Webb* \\ *University of Nottingham, School of Biosciences, Sutton Bonington Campus, Loughborough LE12 5RD, United Kingdom \\ †Roslin Institute (Edinburgh), Roslin, Midlothian EH25 9PS, United Kingdom \\ łProvimi Research and Technology Centre, Lenneke Marelaan 2, 1932 Sint-Stevens-Woluwe, Belgium \\ §ABNA Ltd., ABN House, Oundle Road, Peterborough PE2 9PW, United Kingdom \\ \#Provimi Ltd., Dalton Airfield Industrial Estate, Dalton, Thirsk YO7 3HE, United Kingdom
}

\begin{abstract}
Plasma insulin concentrations influence resumption of ovarian activity in postpartum dairy cows, and plasma insulin can be manipulated by changing dietary starch and fat supply. The objective of this experiment was to investigate the role of dietary amino acids in altering peripheral metabolic hormones and ovarian function. Thirty-two cows were fed a standard diet from calving until $40 \mathrm{~d}$ in milk (DIM), and then 8 cows were transferred to each of 4 dietary treatments until 70 DIM. The 4 diets were designed to supply either low (diets 1 and 2) or high (diets 3 and 4) levels of metabolizable protein (MP), containing either low (diet 1 and 3 ) or high (diets 2 and 4) proportions of Leu. Leucine was manipulated with heat-treated lupins and corn gluten meal. Estrus was synchronized at 60 DIM. Between 60 and 70 DIM, energy intake and energy balance were similar among diet groups, although cows receiving high MP containing high Leu had a greater milk yield than other groups (means: 37.8, 37.1, 37.4, 39.4 \pm standard error $0.85 \mathrm{~kg} / \mathrm{d}$ for diets 1 to 4 , respectively). Interactions between MP and Leu were found for insulin, glucagon, and the ratio between them. Insulin was not affected by Leu in diets with low MP but was decreased by greater Leu in diets with high MP (means: 0.37, 0.32, 0.46, $0.39 \pm$ SE 0.031 $\mathrm{ng} / \mathrm{mL}$ for diets 1 to 4 , respectively). Glucagon was not affected by MP in diets with low Leu but was increased by greater MP in diets with high Leu (means: 92, 81, $88,95 \pm \mathrm{SE} 6.0 \mathrm{pg} / \mathrm{mL}$ for diets 1 to 4 , respectively). For the low-MP treatments, the insulin-to-glucagon ratio was greater with high Leu; for the high-MP treatments, the insulin-to-glucagon ratio was greater with low Leu (means: 4.28, 5.42, 5.16, $4.22 \pm$ SE 0.456 for diets 1 to 4 , respectively). There was no effect of MP or Leu on ovarian follicle numbers or reproductive hormones. Based
\end{abstract}

Received January 18, 2008.

Accepted May 12, 2008.

${ }^{1}$ Corresponding author: Phil.Garnsworthy@nottingham.ac.uk on hormonal and ovarian responses, we conclude that altering metabolic hormones through manipulation of amino acid supply and balance is unlikely to have a significant effect on ovarian function in dairy cows.

Key words: dairy cow, insulin-to-glucagon ratio, amino acid, ovarian function

\section{INTRODUCTION}

Metabolic hormones influence dairy cow fertility by interacting with reproductive hormones that control ovarian function and reproductive events (Butler, 2003; Webb et al., 2004; Garnsworthy et al., 2008c). Selection of dairy cows for high milk production was associated with a longer interval from parturition to first ovulation, high plasma concentrations of growth hormone (GH) and BHBA, and low plasma concentrations of glucose and insulin (Gutierrez et al., 2006; Chagas et al., 2007). Feeding a diet to increase circulating insulin concentrations for the first 50 DIM increased the proportion of dairy cows ovulating during this period (Gong et al., 2002). The effect was observed in cows of both high and low genetic merit and was not associated with milk yield or energy balance. Because insulin is affected by many dietary and animal factors, it is desirable to explore different approaches to insulin manipulation so that optimum strategies can be developed to improve reproductive performance.

We conducted a series of experiments to investigate responses to diets designed to alter metabolic hormones, particularly insulin, in high-yielding dairy cows. The overall objective was to investigate hormonal responses to diet at a critical stage of the breeding period (40 to 70 DIM) and to relate these to measures of ovarian function. In the first experiment (Garnsworthy et al., 2008a), increasing dietary starch concentration and decreasing dietary fat concentration increased plasma insulin-to-glucagon ratio, numbers of small follicles, and size of the ovulatory follicle. In the second experiment (Garnsworthy et al., 2008b), increasing dietary 
fat concentration while maintaining dietary starch concentration had a negative effect on plasma insulin but did not affect follicle numbers except for a decrease in small follicle numbers when cows were fed no added fat. Although these studies show that changes in dietary starch and fat influence plasma insulin, there are several ways in which dietary protein supply might be a factor that influences metabolic hormones. Amino acids provide a source of glucose through gluconeogenesis (Danfaer et al., 1995). Amino acid supply can influence milk secretion and mobilization of body fat (Garnsworthy and Jones, 1987), thereby providing further indirect routes for influencing insulin secretion. Branch chain amino acids have several roles in metabolism that could influence insulin: Leu is ketogenic, Ile is both ketogenic and glucogenic, and Val is glucogenic, and they affect secretion of metabolic hormones, especially prolactin and insulin (Lal and Chugh, 1995). Leucine is of particular interest, because it directly stimulates insulin mRNA levels in pancreatic cells (Docherty and Clark, 1994).

The objective of this experiment was to investigate the role of dietary amino acids in altering peripheral metabolic hormones and ovarian function. The specific aim was to test the hypothesis that increasing the supply of metabolizable Leu will increase plasma insulin concentrations in lactating cows that are in negative MP balance. In addition to metabolic hormones and indicators of ovarian function (follicle dynamics and steroid hormones), responses in milk production and plasma metabolites are reported.

\section{MATERIALS AND METHODS}

\section{Animals, Management, and Diets}

Thirty-two multiparous Holstein dairy cows were group-housed and individually fed through electronic feeders from calving until 70 DIM. Diets were fed as TMR (Garnsworthy et al., 2008a). Each cow received $0.5 \mathrm{~kg}$ of a pelleted dairy compound feed at each milking (DM 872 g/kg; ME 11.7 MJ/kg of DM; CP $208 \mathrm{~g} / \mathrm{kg}$ of DM).

Cows were fed a standard TMR (Table 1) during a baseline period from calving until 40 DIM and were assigned to 8 blocks of 4 cows on the basis of calving date. Blocks were balanced for mean milk yield recorded during the first 20 DIM. From 38 DIM, cows were transferred at random within blocks to 4 treatment diets (Table 1) over a period of $2 \mathrm{~d}$. The 4 treatment diets were designed to supply $\mathrm{ME}$ requirements for a milk production of $45 \mathrm{~L} / \mathrm{d}$, with either low or high levels of MP, containing low or high proportions of Leu. Greater proportions of Leu were achieved by including heat-treated lupins and corn gluten meal in the diets. Treatment diets were fed from 40 to 70 DIM.

\section{Feed Analysis}

Feed intake was recorded daily, and diet samples were taken for analysis at weekly intervals (Garnsworthy et al., 2008a). To calculate digestible undegradable Leu concentrations, values for Leu in rumen escape protein were taken from Robinson $(1998 \mathrm{a}, \mathrm{b}, \mathrm{c})$ for all dietary ingredients except lupins. For lupins, Leu content $(8.1 \%$ of $\mathrm{CP})$ was measured in residues after $12 \mathrm{~h}$ of rumen incubation in nylon bags.

\section{Estrous Synchronization}

Estrous cycles were synchronized to 60 DIM. Ovarian activity was then monitored by daily transrectal ultrasound scanning from 61 to 70 DIM (Garnsworthy et al., 2008a).

\section{Performance Measurements}

Milk yield was recorded daily from calving until 70 DIM. Milk samples were collected at 30, 38, and 60 to 70 DIM and were analyzed for fat, protein, and lactose contents (Garnsworthy et al., 2008a) Body weight and BCS were recorded weekly (Garnsworthy et al., 2008a).

\section{Blood Sampling}

Blood samples were collected by jugular venipuncture at $0900 \mathrm{~h}$ ( $2 \mathrm{~h}$ after morning feeding), at 30 and 35 DIM for determination of baseline values of hormones, metabolites, and amino acids. Further blood samples were collected daily at $0900 \mathrm{~h}$ from 60 to 70 DIM for determination of daily variation in hormones, metabolites, and amino acids (Garnsworthy et al., 2008a). Blood samples were analyzed for the following hormones: insulin, GH, IGF-I, glucagon, leptin, estradiol, and progesterone (Garnsworthy et al., 2008a). Blood samples were also analyzed for the following: albumin, total protein, globulin, urea N, glucose, BHBA, NEFA, magnesium, and inorganic phosphorus (Garnsworthy et al., 2008a).

Amino acid analysis of blood and feed samples was performed using a method provided by BOCM PAULS Ltd. (Ipswich, UK) laboratory. Samples were oxidized with a hydrogen peroxide-formic acid-phenol mixture. Excess oxidation reagent was decomposed with sodium metabisulfite. The oxidized samples were hydrolyzed with $6 M$ hydrochloric acid for $24 \mathrm{~h}$. The hydrolysate was adjusted to $\mathrm{pH} 2.2$, centrifuged, and filtered. Amino 
Table 1. Formulation and chemical composition of treatment diets supplying 2 levels of MP and 2 concentrations of Leu

\begin{tabular}{|c|c|c|c|c|c|}
\hline Formulation (g/kg of DM) & \multicolumn{2}{|c|}{ Low MP } & \multicolumn{2}{|c|}{ High MP } & Base $^{1}$ \\
\hline Grass $^{2}$ silage & 337 & 334 & 342 & 342 & 338 \\
\hline Distillers grains ensiled & 97 & 96 & 98 & 98 & 97 \\
\hline Corn gluten meal CP 600 & 0 & 20 & 0 & 41 & 30 \\
\hline Soypass & 0 & 0 & 60 & 20 & 0 \\
\hline Sugarbeet pulp molassed & 207 & 164 & 105 & 84 & 123 \\
\hline Soyabean meal Brazilian & 30 & 0 & 20 & 20 & 50 \\
\hline Rapeseed meal & 20 & 0 & 62 & 0 & 58 \\
\hline Fat supplement ${ }^{3}$ & 14 & 14 & 14 & 14 & 14 \\
\hline Minerals and vitamins ${ }^{4}$ & 11 & 11 & 11 & 11 & 11 \\
\hline Urea & 4 & 0 & 2 & 0 & 0 \\
\hline Total & 1,000 & 1,000 & 1,000 & 1,000 & 1,000 \\
\hline Bypass starch (g/kg of DM) & 89 & 104 & 85 & 100 & 88 \\
\hline Sugars $(g / k g$ of $D M)$ & 63 & 58 & 63 & 55 & 63 \\
\hline $\mathrm{Fat}^{6}(\mathrm{~g} / \mathrm{kg}$ of $\mathrm{DM})$ & 47 & 47 & 48 & 51 & 48 \\
\hline $\mathrm{CP}(\mathrm{g} / \mathrm{kg}$ of $\mathrm{DM})$ & 161 & 152 & 199 & 181 & 158 \\
\hline Effective $\operatorname{RDP}^{7}(\mathrm{~g} / \mathrm{kg}$ of $\mathrm{DM})$ & 101 & 89 & 119 & 99 & 98 \\
\hline Digestible RUP ${ }^{7}$ (g/kg of DM) & 48 & 50 & 65 & 66 & 48 \\
\hline Leu $(\mathrm{g} / \mathrm{kg}$ of $\mathrm{DM})$ & 33 & 59 & 117 & 167 & 93 \\
\hline Digestible undegradable leucine $^{8}(\mathrm{~g} / \mathrm{kg}$ of $\mathrm{DM})$ & 11 & 21 & 52 & 82 & 41 \\
\hline
\end{tabular}

${ }^{1}$ Diet fed during baseline period from calving until 40 DIM.

${ }^{2}$ Perennial ryegrass (Lolium perenne).

${ }^{3}$ Megalac, calcium salts of palm fatty acids: Volac International, Royston, United Kingdom.

${ }^{4}$ Minline Super Phosphate, BOCM Pauls, Ipswich, United Kingdom: calcium, 18\%; phosphorus, 10\%; magnesium, 5\%; salt, 17\%; copper, $2,000 \mathrm{mg} / \mathrm{kg}$; manganese, 4,000 mg/kg; cobalt, $100 \mathrm{mg} / \mathrm{kg}$; zinc, $6,000 \mathrm{mg} / \mathrm{kg}$; iodine, $500 \mathrm{mg} / \mathrm{kg} ;$ selenium, $25 \mathrm{mg} / \mathrm{kg} ;$ vitamin A, 400,000 IU/ $\mathrm{kg}$; vitamin $\mathrm{D}_{3}, 80,000 \mathrm{IU} / \mathrm{kg}$; vitamin $\mathrm{E}, 1,000 \mathrm{mg} / \mathrm{kg}$.

${ }^{5}$ Calculated from laboratory analysis of components.

${ }^{6}$ Acid hydrolysis method.

${ }^{7}$ Calculated from rumen degradability values determined in situ and laboratory analysis of components.

${ }^{8}$ Values for Leu content of rumen escape protein from Robinson (1998a,b,c) except for lupins, for which the value (8.1\% of CP) was measured in nylon bag residues after a 12 -h rumen incubation.

acids were separated by ion exchange chromatography (Biochrom 20+ Amino Acid Analyzer, Biochrom Ltd., Cambridge, UK) and determined by reaction with ninhydrin using photometric detection at $570 \mathrm{~nm}(440 \mathrm{~nm}$ for Pro).

\section{Statistical Analyses}

Metabolizable energy balance was calculated for each cow (Garnsworthy et al., 2008a). Dietary effects on mean observations during the treatment period (60 to 70 DIM) were examined by analysis of covariance, using Genstat 8 (Lawes Agricultural Trust, Rothamsted, UK), with a factorial design looking at the main effects of MP and Leu levels, using mean observations during the standardization period (30 to 38 DIM) as covariates. Where main treatment or interaction effects were significant, group means were compared by least significance difference test. Reproductive data, which were not normally distributed, were analyzed by using generalized linear models with a Poisson error distribution and log link function. Simple correlation coefficients were determined to examine relationships among variates across individuals, using mean data for each cow.

\section{RESULTS}

\section{Intake, Milk Production, and Body Weight}

The main effects of dietary treatments on performance measurements are shown in Table 2. Intakes of 
Table 2. Least squares means from 60 to 70 DIM, adjusted by covariance for values between 30 and 38 DIM, for intakes, milk production and composition, BW, and BCS in cows $(\mathrm{n}=8)$ given diets supplying 2 levels of MP and 2 concentrations of Leu

\begin{tabular}{|c|c|c|c|c|c|c|c|c|}
\hline Item & Low Leu & High Leu & Low Leu & High Leu & $\mathrm{SED}^{1}$ & MP & Leu & $\mathrm{MP} \times$ Leu \\
\hline $\mathrm{ME}(\mathrm{MJ} / \mathrm{d})$ & 261 & 257 & 261 & 265 & 12.6 & 0.637 & 0.959 & 0.685 \\
\hline Starch (kg/d) & $4.3^{\mathrm{a}}$ & $4.8^{\mathrm{b}}$ & $4.2^{\mathrm{a}}$ & $4.8^{\mathrm{b}}$ & 0.23 & 0.455 & 0.001 & 0.799 \\
\hline NDF (kg/d) & 7.9 & 7.5 & 7.7 & 7.0 & 0.39 & 0.242 & 0.157 & 0.614 \\
\hline Fat $(\mathrm{kg} / \mathrm{d})$ & 1.0 & 1.0 & 1.0 & 1.1 & 0.05 & 0.126 & 0.608 & 0.196 \\
\hline Milk yield (kg/d) & $37.8^{\mathrm{a}}$ & $37.1^{\mathrm{a}}$ & $37.4^{\mathrm{a}}$ & $39.4^{\mathrm{b}}$ & 0.85 & 0.145 & 0.307 & 0.035 \\
\hline Fat $(\mathrm{g} / \mathrm{kg})$ & 37.9 & 37.3 & 37.3 & 36.7 & 1.80 & 0.621 & 0.642 & 0.992 \\
\hline Protein (g/kg) & 29.5 & 29.2 & 29.8 & 28.7 & 0.61 & 0.887 & 0.107 & 0.364 \\
\hline Lactose (g/kg) & 46.6 & 46.8 & 46.3 & 46.1 & 0.66 & 0.265 & 0.996 & 0.626 \\
\hline Fat yield (kg/d) & 1.43 & 1.35 & 1.42 & 1.45 & 0.091 & 0.562 & 0.671 & 0.399 \\
\hline Protein yield $(\mathrm{kg} / \mathrm{d})$ & 1.11 & 1.08 & 1.11 & 1.13 & 0.035 & 0.283 & 0.717 & 0.400 \\
\hline Lactose yield $(\mathrm{kg} / \mathrm{d})$ & 1.77 & 1.74 & 1.72 & 1.81 & 0.052 & 0.754 & 0.450 & 0.099 \\
\hline MP balance (g/d) & $-38^{\mathrm{a}}$ & $-58^{\mathrm{a}}$ & $101^{\mathrm{b}}$ & $173^{\mathrm{b}}$ & 70.3 & $<0.001$ & 0.612 & 0.362 \\
\hline
\end{tabular}

${ }^{\mathrm{a}, \mathrm{b}}$ Means in the same row without a common superscript differ $(P<0.05)$.

${ }^{1} \mathrm{SED}=$ standard error of the difference between treatment means

CP and MP were significantly greater for diets with the greater level of MP. There was no effect of treatment on intakes of DM, ME, NDF, or fat. Due to differences in the starch content of ingredients, the diets designed to have a greater concentration of Leu resulted in greater intakes of starch.

For milk yield, there was a significant interaction between MP and Leu; cows on the treatment with high MP and high Leu had a significantly greater milk yield than cows on the other 3 treatments. There was no effect of dietary treatment on milk composition or yield of milk constituents. There was no difference among treatment groups in BW or BCS. Cows given the highMP diets lost BW, and cows given the low-MP diets gained weight (Table 2), although there was no effect on change in BCS.

Calculated ME balance was similar for all treatments. Calculated MP balance was negative for diets supplying the low level of MP and positive for diets supplying the high level of MP (Table 2).

\section{Plasma Amino Acids}

Plasma concentrations of amino acids are shown in Table 3. Concentrations of most amino acids were unaffected by dietary treatment. The main effect of MP level was significant for plasma concentrations of 3-methyl His and Met, which were lower for cows of- fered diets with high MP (Table 3). In contrast, plasma concentrations of Leu and Pro were greater for cows offered diets with high MP (Table 3). The main effect of Leu level was significant for plasma Leu concentration, which was greater for cows offered diets with high Leu (Table 3). Interactions between MP and Leu levels were significant for Ala, which was lower with high MP in cows offered diets with high Leu, and taurine, which was greatest for cows offered high MP and low Leu but lowest for cows offered high MP and high Leu (Table $3)$.

\section{Metabolic Hormones and Metabolites}

Significant interactions between MP and Leu were found for plasma insulin, glucagon, and the ratio between them (Table 4). Insulin was greater for cows on the treatment with high MP and low Leu than for cows on the 2 treatments with low MP and low Leu or high MP and high Leu. Glucagon was greater for cows on the treatment with high MP and high Leu than for cows on the treatment with low MP and high Leu. For the low-MP treatments, the insulin-to-glucagon ratio was greater with high Leu; for the high-MP treatments, the insulin-to-glucagon ratio was greater with low Leu. There was no effect of diet on leptin, GH, or IGF-I.

Plasma albumin was lower for cows offered diets with high MP than for cows provided low MP (Table 
Table 3. Least squares means from 60 to 70 DIM, adjusted by covariance for values between 30 and 38 DIM, for plasma concentrations ( $\mu M$ ) of amino acids in cows $(n=8)$ given diets supplying 2 levels of MP and 2 concentrations of Leu

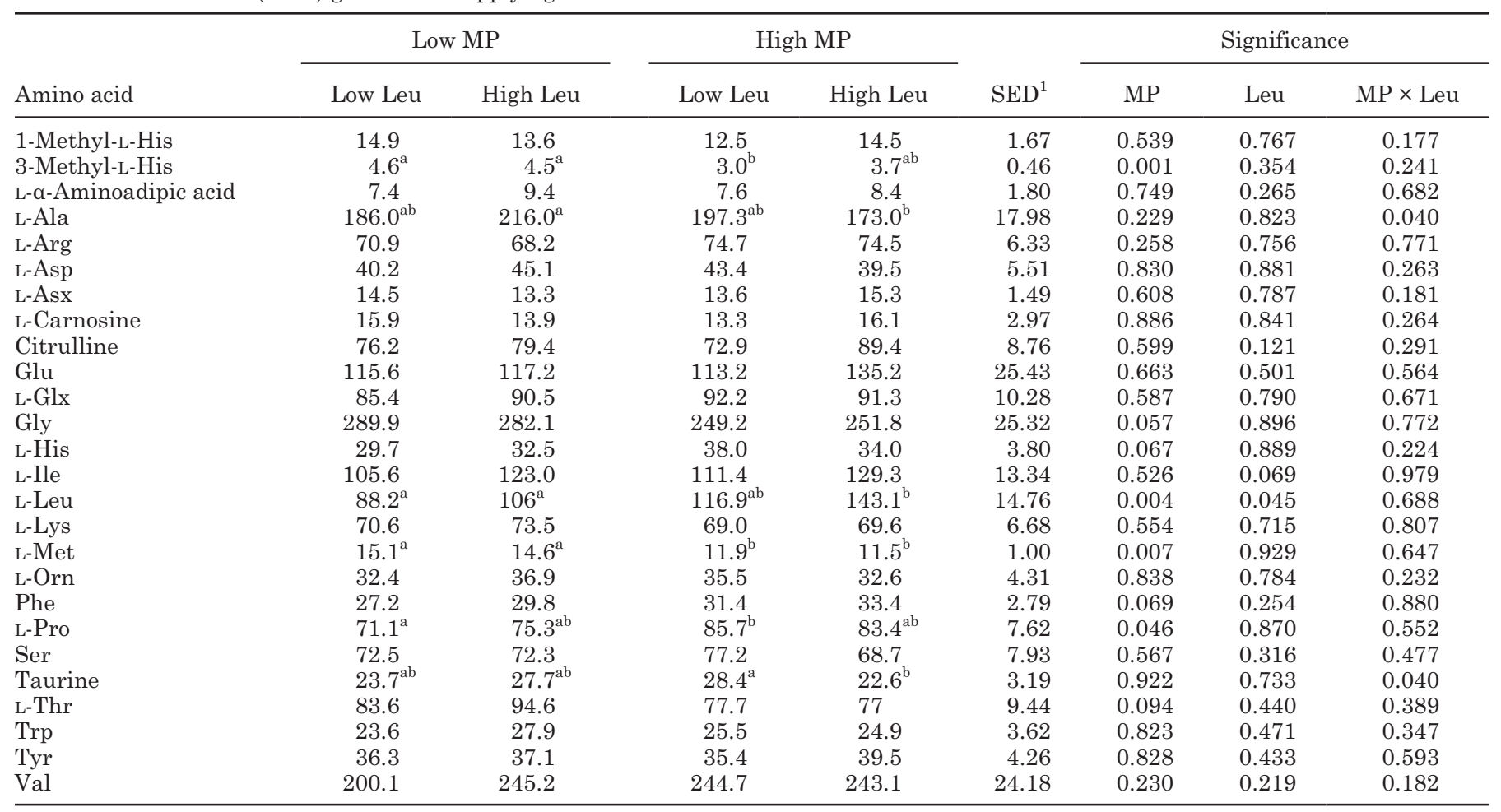

${ }^{\mathrm{a}, \mathrm{b}}$ Means in the same row without a common superscript differ $(P<0.05)$.

${ }^{1} \mathrm{SED}=$ standard error of the difference between treatment means.

4). Plasma globulin and total protein were not affected by dietary treatment. Plasma urea $\mathrm{N}$ was greater for cows fed high MP $(P<0.001)$ than cows fed low MP (Table 4). Plasma glucose and magnesium were lower for cows fed high MP than cows fed low MP (Table 4), but BHBA, NEFA, and inorganic phosphorus were unaffected by treatment.

\section{Ovarian Activity}

Ovulation was detected by ultrasound scanning or assessment of estradiol and progesterone concentrations, or both, in 24 of the 32 cows. In the remaining 8 cows $(3 \times$ low MP, low leu; $1 \times$ low MP, high leu; $2 \times$ high MP, low Leu; $2 \times$ high MP, high Leu), ovulation was not detected, and a lack of progesterone increase suggested that ovulation had not occurred. These cows were excluded from further analysis of reproductive variables.

There was no difference among diet groups in the timing of ovulation, and mean $( \pm \mathrm{SE})$ day of ovulation was $4.1 \pm 0.3$ (range 2 to 7 ) $\mathrm{d}$ after removal of a controlled internal drug release insert. There was no difference among diet groups in progesterone, estradiol, number of follicles, size of the ovulatory follicle, or size of the developing corpus luteum (Table 5).

\section{Relationships Among Variables (Across Individuals)}

Plasma insulin was positively correlated with BW (r $=0.370)$ and plasma glucagon $(r=0.390)$ and negatively correlated with GH $(r=-0.432)$. Plasma glucagon was negatively correlated with plasma total protein content $(\mathrm{r}=-0.414)$. Plasma IGF-I was positively correlated with milk protein concentration $(\mathrm{r}=0.353)$, BW change $(r=0.366)$, and BCS $(r=0.456)$ and negatively correlated with milk fat yield $(\mathrm{r}=-0.351)$ and MP balance $(\mathrm{r}=-0.382)$. Plasma leptin was positively correlated with plasma albumin $(r=0.366)$. Growth hormone was positively correlated with DMI $(r=0.383)$, milk yield $(r=0.416)$, and MP balance $(r=0.421)$ and negatively correlated with milk protein concentration $(r=-0.417)$, BCS $(r=-0.439)$, and plasma glucose $(r=-0.471)$.

Neither follicle numbers nor size was related to any of the other variables measured. Yet, there was a negative relationship between change in BCS and preovulatory plasma estradiol concentration $(\mathrm{r}=-0.432 ; P<$ $0.05)$.

\section{DISCUSSION}

The dietary treatments produced the desired differences in MP balance, which were accompanied by 
Table 4. Least squares means from 60 to 70 DIM, adjusted by covariance for values between 30 and 38 DIM, for plasma concentrations of metabolic hormones and metabolites in cows $(n=8)$ given diets supplying 2 levels of MP and 2 concentrations of Leu

\begin{tabular}{|c|c|c|c|c|c|c|c|c|}
\hline \multirow[b]{2}{*}{ Item } & \multicolumn{2}{|c|}{ Low MP } & \multicolumn{2}{|c|}{ High MP } & \multirow[b]{2}{*}{$\mathrm{SED}^{1}$} & \multicolumn{3}{|c|}{ Significance } \\
\hline & Low Leu & High Leu & Low Leu & High Leu & & MP & Leu & $\mathrm{MP} \times$ Leu \\
\hline Insulin:glucagon ratio & $4.28^{\mathrm{ab}}$ & $5.42^{\mathrm{c}}$ & $5.16^{\mathrm{bc}}$ & $4.22^{\mathrm{a}}$ & 0.456 & 0.593 & 0.765 & 0.003 \\
\hline Leptin (ng/mL) & 0.75 & 0.67 & 0.83 & 0.65 & 0.11 & 0.731 & 0.131 & 0.417 \\
\hline GH (ng/mL) & 9.9 & 10.1 & 8.4 & 10.3 & 1.58 & 0.790 & 0.781 & 0.578 \\
\hline Globulin (g/L) & 34.1 & 33.8 & 33.7 & 35.0 & 1.84 & 0.736 & 0.689 & 0.551 \\
\hline Total protein $(\mathrm{g} / \mathrm{L})$ & 69.4 & 70.2 & 67.8 & 67.1 & 2.67 & 0.227 & 0.991 & 0.700 \\
\hline Urea N (mmol/L) & $2.38^{\mathrm{a}}$ & $2.47^{\mathrm{a}}$ & $3.21^{\mathrm{b}}$ & $3.35^{\mathrm{b}}$ & 0.241 & $<0.001$ & 0.498 & 0.879 \\
\hline Glucose $(\mathrm{mmol} / \mathrm{L})$ & $3.14^{\mathrm{a}}$ & $3.10^{\mathrm{ab}}$ & $3.00^{\mathrm{ab}}$ & $2.99^{b}$ & 0.082 & 0.040 & 0.676 & 0.907 \\
\hline BHBA (mmol/L) & 0.64 & 0.63 & 0.66 & 0.75 & 0.089 & 0.251 & 0.524 & 0.457 \\
\hline NEFA (mmol/L) & 0.19 & 0.20 & 0.24 & 0.20 & 0.027 & 0.284 & 0.517 & 0.212 \\
\hline $\mathrm{Mg}(\mathrm{mmol} / \mathrm{L})$ & $0.93^{\mathrm{a}}$ & $0.95^{\mathrm{a}}$ & $0.87^{\mathrm{b}}$ & $0.87^{\mathrm{b}}$ & 0.041 & 0.023 & 0.669 & 0.739 \\
\hline
\end{tabular}

${ }^{a-c}$ Means in the same row without a common superscript differ $(P<0.05)$.

${ }^{1} \mathrm{SED}=$ standard error of the difference between treatment means.

differences in plasma amino acid concentrations. Furthermore, the diets designed to supply a greater level of metabolizable Leu resulted in significant increases in plasma Leu concentrations.

The main hypothesis tested in this experiment was that increasing the supply of metabolizable Leu will increase plasma insulin concentration in lactating cows that are in negative MP balance. Although high Leu caused a slight augmentation in insulin with the low-MP diets, the difference was not significant; therefore, the hypothesis was not proven. Furthermore, for cows in positive MP balance (high-MP diets), greater Leu increased milk yield and decreased insulin. The insulin-to-glucagon ratio increased with high Leu for the low-MP diets and decreased with high Leu for the high-MP diets.
Within the low MP level, the increase in insulin-toglucagon ratio with greater Leu was associated with a greater mean starch intake, which could be expected to increase the ratio. The difference in starch intake was small, however, compared with differences observed in previous experiments of this series (Garnsworthy et al., 2008a,b) in which there was no response in the insulin-to-glucagon ratio within this part of the starch intake range. Furthermore, at the individual cow level, there was no relationship between starch intake and the insulin-to-glucagon ratio. Insulin responses to Leu sources were reported for lupins in sheep (Downing et al., 1995) and for corn gluten meal in dairy cows (Landau et al., 2000); these were the raw materials used to change dietary Leu in the current experiment. We conclude that the increase in insulin-to-glucagon ratio

Table 5. Treatment means ${ }^{1}$ relative to a synchronized estrus at around 60 DIM for plasma concentrations of estradiol before ovulation and progesterone from d 3 to 5 postovulation, as well as follicle ${ }^{2}$ numbers, ovulatory follicle diameter, and corpus luteum (CL) diameter in cows given diets supplying 2 levels of MP and 2 concentrations of Leu

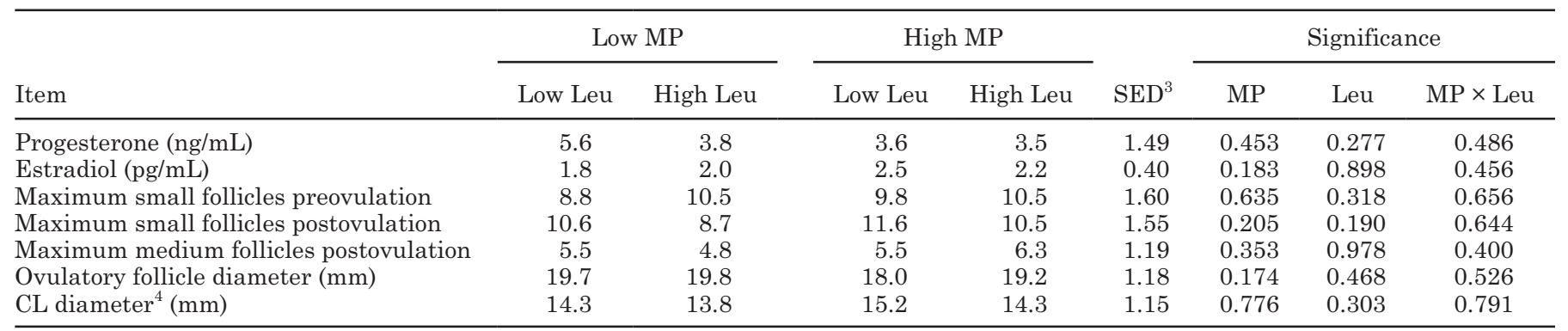

${ }^{1}$ Values are backtransformed from generalized linear models with Poisson error distribution and log link function.

${ }^{2}$ Small follicles $<5 \mathrm{~mm}$; medium-sized follicles 5 to $10 \mathrm{~mm}$.

${ }^{3} \mathrm{SED}=$ standard error of the difference between treatment means.

${ }^{4}$ On d 5 after ovulation. 
observed with the low-MP, high-Leu diet was caused not by the small difference in starch intake but by the change in Leu or MP supply.

Within the high MP level, cows responded to high Leu with significant decreases in both insulin and the insulin-to-glucagon ratio. The most likely explanation is the significant increase in milk yield in response to Leu. Greater milk yields increase the use of glucose for lactose synthesis, thereby decreasing stimulation of insulin secretion (Bauman, 2000). A similar milk yield response was observed by Allison and Garnsworthy (2002), in which, compared with a control diet, cows increased milk yield when supplemented with a vegetable protein blend but not when supplemented with fishmeal. The main difference between the 2 protein supplements was Leu, which was calculated to be limiting in the control and fishmeal treatments.

The greater plasma urea $\mathrm{N}$ concentrations observed with high-MP diets compared with low-MP diets suggest greater use of amino acids for gluconeogenesis with the high-MP diets. Bach et al. (2000) found that dairy cows fed on high-MP diets had greater plasma urea levels; furthermore, they found that plasma insulin concentration was greater with their high-MP diets, which is supported by the insulin response to MP level in the low-Leu diets of the current study. Danfaer et al. (1995) found a significant increase in glucagon with infusion of amino acids into the mesenteric vein of a goat and concluded that glucagon stimulated gluconeogenesis from amino acids. With the high-Leu diets, glucagon increased in response to MP level. This supports observations of Blouin et al. (2002), who observed that a smaller proportion of glucagon was removed by the liver when cows were fed a high-MP diet.

Across individual cows, GH was positively related to milk yield and DMI and was negatively related to insulin and BCS, as would be expected from previous studies (Bauman, 2000; Gong et al., 2002; Gutierrez et al., 2006). Insulin-like growth factor I was not related to either GH or insulin but was related to animal factors such as BW change, BCS, and milk composition, which is consistent with previous experiments in which metabolic hormones were manipulated by nutrition rather than genetics (Garnsworthy et al., 2008a,b).

The positive relationship between insulin and glucagon across individual cows is contrary to changes in group means in response to MP and Leu. For dietary group means, both insulin and glucagon showed significant interactions between MP and Leu, and the 2 hormones responded in opposite directions to changes in MP and Leu. The positive relationship across cows was consistent within all 4 diet groups, which suggests that animal factors such as BW, milk yield, and genetics acted independently of dietary effects. This is con- sistent with changes in insulin and glucagon that were manipulated by alterations in dietary amino acids in the current experiment, whereas previous experiments in this series involved alterations in dietary starch and fatty acids.

In cows that ovulated normally, patterns of preovulatory estradiol concentration and postovulatory luteal function were comparable with earlier studies (Garnsworthy et al., 2008a,b). Overall, there was little effect of MP and Leu on reproductive measures. The negative relationship between change in BCS and preovulatory estradiol suggests improved reproductive function in the face of decreased energy status, which is contrary to observations in other studies (Butler, 2003; Garnsworthy et al., 2008c). Effects of protein nutrition on ovarian and uterine function were reviewed by Butler (1998), who concluded that high dietary protein seems not to affect follicle development or ovulation, an observation supported by the results of the current study. In our studies (Garnsworthy et al., 2008a), insulin-toglucagon ratio was positively related to numbers of small follicles and size of the ovulatory follicle; the absence of such responses could be due to associated negative effects of obligate urea $\mathrm{N}$ generation during gluconeogenesis from amino acids.

\section{CONCLUSIONS}

The results of this experiment demonstrate that effects of dietary amino acid supply on metabolic hormones depend on total quantity of MP. Significant interactions were observed between the effects of MP and Leu on plasma insulin and glucagon. Increasing Leu in diets with low MP increased the insulin-to-glucagon ratio, whereas increasing Leu in diets with high MP decreased the insulin-to-glucagon ratio. The high-Leu, high-MP responses were associated with changes in milk yield.

Physiologically, these observations suggest that Leu with low MP inhibits glucagon secretion. The insulinto-glucagon ratio depends on both the total supply of MP and the balance of amino acids.

Our previous studies have shown that increasing plasma insulin concentrations by increasing dietary starch concentration can advance resumption of ovarian activity postpartum and that the insulin-toglucagon ratio was positively related to numbers of small follicles and size of the ovulatory follicle. Based on hormonal and ovarian responses in the current study, we conclude that altering metabolic hormones through manipulation of amino acid supply and balance is unlikely to have a significant effect on ovarian function. 


\section{ACKNOWLEDGMENTS}

This study was part of Project LK0646 in the LINK Sustainable Livestock Production program, which was funded by the Scottish Executive Environment and Rural Affairs Department (SEERAD), Edinburgh, UK; ABNA Ltd., Peterborough, UK; BOCM PAULS Ltd., Ipswich, UK; and Provimi Ltd., Sint-Stevens-Woluwe, Belgium. In addition to the authors, the following people served on the Programme Management Committee and made valuable contributions to the design and interpretation of the experiment: A. Boydell (BOCM PAULS Ltd.), A. Flint (University of Nottingham), D. Garwes (Department for Environment, Food and Rural Affairs, London, UK), and D. Leaver (Royal Agricultural College, Cirencester, UK). We thank the following people for technical assistance: H. Russell (University of Nottingham), W. Lee (Roslin Institute), J. Nixon (Roslin Institute), G. Baxter (Roslin Institute), M. Mitchell (University of Nottingham), D. Scholey (University of Nottingham), M. Hunter (University of Nottingham), D. Whitaker (University of Edinburgh), and C. Smith (National Milk Records, Chippenham, UK). Statistical advice was provided by J. Craigon (University of Nottingham).

\section{REFERENCES}

Allison, R. D., and P. C. Garnsworthy. 2002. Increasing the digestible undegraded protein intake of lactating dairy cows by feeding fishmeal or a rumen protected vegetable protein blend. Anim. Feed Sci. Technol. 96:69-81.

Bach, A., G. B. Huntington, S. Calsamiglia, and M. D. Stern. 2000. Nitrogen metabolism of early lactation cows fed diets with two different levels of protein and different amino acid profiles. J. Dairy Sci. 83:2585-2595.

Bauman, D. E. 2000. Regulation of nutrient partitioning during lactation: Homeostasis and homeorhesis revisited. Pages 311328 in Ruminant Physiology: Digestion, Metabolism, Growth and Reproduction. P. B. Cronje, ed. CABI Publishing, Wallingford, UK.

Blouin, J. P., J. F. Bernier, C. K. Reynolds, G. E. Lobley, P. Dubreuil, and H. Lapierre. 2002. Effect of supply of metabolizable protein on splanchnic fluxes of nutrients and hormones in lactating dairy cows. J. Dairy Sci. 85:2618-2630.

Butler, W. R. 1998. Review: Effect of protein nutrition on ovarian and uterine physiology in dairy cattle. J. Dairy Sci. 81:2533-2539.

Butler, W. R. 2003. Energy balance relationships with follicular development, ovulation and fertility in postpartum dairy cows. Livest. Prod. Sci. 83:211-218.

Chagas, L. M., J. J. Bass, D. Blache, C. R. Burke, J. K. Kay, D. R. Lindsay, M. C. Lucy, G. B. Martin, S. Meier, F. M. Rhodes, J. R.
Roche, W. W. Thatcher, and R. Webb. 2007. New perspectives on the roles of nutrition and metabolic priorities in the subfertility of high-producing dairy cows. J. Dairy Sci. 90:4022-4032.

Danfaer, A., V. Tetens, and N. Agergaard. 1995. Review and an experimental study on the physiological and quantitative aspects of gluconeogenesis in lactating ruminants. Comp. Biochem. Physiol. 111:201-210.

Docherty, K., and A. R. Clark. 1994. Nutrient regulation of insulin gene expression. FASEB J. 8:20-27.

Downing, J. A., J. Joss, P. Connell, and R. J. Scaramuzzi. 1995. Ovulation rate and the concentrations of gonadotropic and metabolic hormones in ewes fed lupin grain. J. Reprod. Fertil. 103:137-145.

Garnsworthy, P. C., and G. P. Jones. 1987. The influence of body condition at calving and dietary protein supply on voluntary food intake and performance in dairy cows. Anim. Prod. 44:347353.

Garnsworthy, P. C., A. Lock, G. E. Mann, K. D. Sinclair, and R. Webb. 2008a. Nutrition, metabolism and fertility in dairy cows: 1. Dietary energy source and ovarian function. J. Dairy Sci. 91:3814-3823.

Garnsworthy, P. C., A. Lock, G. E. Mann, K. D. Sinclair, and R. Webb. 2008b. Nutrition, metabolism and fertility in dairy cows: 2. Dietary fat content and ovarian function. J. Dairy Sci. 91:3824-3833.

Garnsworthy, P. C., K. D. Sinclair, and R. Webb. 2008c. Integration of physiological mechanisms that influence fertility in dairy cows. Animal 2:1144-1152.

Gong, J. G., W. J. Lee, P. C. Garnsworthy, and R. Webb. 2002. Effect of dietary-induced increases in circulating insulin concentrations during the early postpartum period on reproductive function in dairy cows. Reproduction 123:419-427.

Gutierrez, C. G., J. G. Gong, T. A. Bramley, and R. Webb. 2006. Selection on predicted breeding value for milk production delays ovulation independently of changes in follicular development, milk production and body weight. Anim. Reprod. Sci. 95:193205.

Lal, H., and K. Chugh. 1995. Metabolic and regulatory effects of branched chain amino acid supplementation. Nutr. Res. 15:1717-1733.

Landau, S., R. Braw-Tal, M. Kaim, A. Bor, and I. Bruckental. 2000. Preovulatory follicular status and diet affect the insulin and glucose content of follicles in high-yielding dairy cows. Anim. Reprod. Sci. 64:181-197.

Robinson, P. H. 1998a. Amino acids in rumen escape protein: 1. Forage and plant source by-products. http://animalscience.ucdavis.edu/ faculty/robinson/Articles/FullText/FeedstuffEvaluation.htm Accessed Jan. 11, 2008.

Robinson, P. H. 1998b. Amino acids in rumen escape protein: 2 Grains and whole seeds. http://animalscience.ucdavis.edu/ faculty/robinson/Articles/FullText/FeedstuffEvaluation.htm Accessed Jan. 11, 2008.

Robinson, P. H. 1998c. Amino acids in rumen escape protein: 3. Plant and non-plant source protein meals. http://animalscience.ucdavis. edu/faculty/robinson/Articles/FullText/FeedstuffEvaluation.htm Accessed Jan 11, 2008.

Webb, R., P. C. Garnsworthy, J. G. Gong, and D. G. Armstrong. 2004. Control of follicular growth: Local interactions and nutritional influences. J. Anim. Sci. 82(E Suppl.):E63-E74. 